\title{
Experimental warming decreases arbuscular mycorrhizal fungal colonization in prairie plants along a Mediterranean climate gradient
}

Hannah Wilson, Bart R Johnson, Brendan Bohannan, Laurel Pfeifer-Meister, Rebecca Mueller, Scott D Bridgham

Background. Arbuscular mycorrhizal fungi (AMF) provide numerous services to their plant symbionts. Understanding climate change effects on AMF, and the resulting plant responses, is crucial for predicting ecosystem responses at regional and global scales. We investigated how the effects of climate change on AMF-plant symbioses are mediated by soil water availability, soil nutrient availability, and vegetation dynamics. Methods. We used a combination of a greenhouse experiment and a manipulative climate change experiment embedded within a Mediterranean climate gradient in the Pacific Northwest, USA to examine this question. Structural equation modeling was used to determine the direct and indirect effects of experimental warming on AMF colonization. Results. Warming directly decreased AMF colonization across plant species and across the climate gradient of the study region. Other positive and negative indirect effects of warming, mediated by soil water availability, soil nutrient availability, and vegetation dynamics, canceled each other out. Discussion. A warming-induced decrease in AMF colonization would likely have substantial consequences for plant communities and ecosystem function. Moreover, predicted increases in more intense droughts and heavier rains for this region could shift the balance among indirect causal pathways, and either exacerbate or mitigate the negative, direct effect of increased temperature on AMF colonization. 
1 Experimental warming decreases arbuscular mycorrhizal fungal colonization in prairie plants

2 along a Mediterranean climate gradient

3

4 Authors: Hannah E. Wilson ${ }^{1 *}$, Bart R. Johnson ${ }^{2,3}$, Brendan J.M. Bohannan ${ }^{1,3}$, Laurel Pfeifer-

5 Meister $^{1,3}$, Rebecca C. Mueller ${ }^{1}$, Scott D. Bridgham ${ }^{1,3}$

6

$7 \quad{ }^{1}$ Institute of Ecology and Evolution, University of Oregon, Eugene, OR 97403-5289, USA;

$8{ }^{2}$ Department of Landscape Architecture, University of Oregon, Eugene, OR 97403-5234, USA;

$9{ }^{3}$ Environmental Science Institute, University of Oregon, Eugene, OR 97403-5223, USA

10

11 * Corresponding Author: email: hwilson1@uoregon.edu, telephone: 503-510-6437 


\section{Abstract}

14 Background. Arbuscular mycorrhizal fungi (AMF) provide numerous services to their plant 15 symbionts. Understanding climate change effects on AMF, and the resulting plant responses, is 16 crucial for predicting ecosystem responses at regional and global scales. We investigated how the 17 effects of climate change on AMF-plant symbioses are mediated by soil water availability, soil 18 nutrient availability, and vegetation dynamics.

19 Methods. We used a combination of a greenhouse experiment and a manipulative climate 20 change experiment embedded within a Mediterranean climate gradient in the Pacific Northwest, 21 USA to examine this question. Structural equation modeling was used to determine the direct 22 and indirect effects of experimental warming on AMF colonization.

23 Results. Warming directly decreased AMF colonization across plant species and across the 24 climate gradient of the study region. Other positive and negative indirect effects of warming, 25 mediated by soil water availability, soil nutrient availability, and vegetation dynamics, canceled 26 each other out.

27 Discussion. A warming-induced decrease in AMF colonization would likely have substantial consequences for plant communities and ecosystem function. Moreover, predicted increases in more intense droughts and heavier rains for this region could shift the balance among indirect

30 causal pathways, and either exacerbate or mitigate the negative, direct effect of increased 31 temperature on AMF colonization.

32 Key Words: Arbuscular mycorrhizal fungi, climate change, experimental warming, 33 Mediterranean, nutrient availability, Pacific Northwest, plant-nutrient interactions, structural 34 equation models. 
36

37

38

39

40

41

42

43

44

45

46

47

48

49

50

51

52

53

54

55

56

57

58

59

60

61

62

63

64

65

66

\section{Introduction}

Arbuscular mycorrhizal fungi (AMF) are plant symbionts that colonize the roots of the majority of terrestrial plants; they provide enhanced nutrient and water uptake, increased drought and disease resistance, and increased plant productivity in exchange for carbon (C) (Smith \& Read, 2008). AMF are a major contributor to terrestrial carbon and nutrient cycles (Fitter et al., 2000) and are considered an important link between above- and belowground processes (Leake et al., 2004). They can consume up to $20 \%$ of C produced by their plant host (Bago et al., 2000), and the hyphal network can occupy over $100 \mathrm{~m} \mathrm{~cm}^{-3}$ of soil (Miller et al., 1995), making up 20$30 \%$ of the total microbial biomass in terrestrial systems (Leake et al., 2004).

Given the widespread importance of AMF, it is not surprising that recent studies have concluded they may play a major role in mediating plant and ecosystem responses to climate change (Rillig et al., 2002, Drigo et al., 2008; Compant et al., 2010). The majority of studies have observed an increase in AMF colonization in response to experimentally increased $\mathrm{CO}_{2}$ levels and/or temperature (Compant et al., 2010). However, many of these studies were performed with one or a few species of AMF and plant hosts under laboratory or greenhouse conditions (Graham et al., 1982; Baon et al., 1994; Staddon et al., 2004; Heinemeyer et al., 2006). Because AMF recently have been shown to have much higher species diversity than previously estimated (Kivlin et al., 2011), and the benefits of AMF symbioses are not equal among plants (Leake et al., 2004), more studies are needed before generalizations can be made about the responses of $\mathrm{AMF}$ and their plant hosts to climate change.

A number of variables may influence AMF response to climate change. The general positive response of $\mathrm{AMF}$ colonization to increased $\mathrm{CO}_{2}$ levels and temperature could be due to increased plant productivity, resulting in a larger demand for plant nutrients and enhanced production of root exudates (Fitter et al., 2000; Zavalloni et al., 2012). Increased drought severity is a major concern for many regions, and AMF have been shown to enhance resistance to drought and improve water relations (Augé, 2001). However, a number of studies have found that increased drought can have a negative effect on AMF, depending on the species of AMF (Davies et al., 2002), hyphal growth within or outside the roots (Staddon et al., 2003), or the species of plant (Ruiz-Lozano et al., 1995). In a long-term climate manipulation, Staddon et al. (2003) found that increased AMF colonization in response to heat was mediated by soil moisture. Furthermore, they speculated that the effect of soil moisture could have been further 
67 mediated by changes in plant diversity and cover of various species, which were also highly 68 correlated with mycorrhizal measures.

It is well established that a decrease in soil nutrient levels, especially of phosphorus (P)

70 and nitrogen $(\mathrm{N})$, can result in an increase in AMF colonization, whereas excess nutrients can

71 result in lower colonization (Mosse \& Phillips, 1971; Smith \& Read, 2008). Thus, increased

72 nutrient mineralization due to experimental warming could influence AMF growth (Rillig et al.,

73 2002). Moreover, the ratio of $\mathrm{N}$ to $\mathrm{P}$ availability may also affect AMF responses to climate

74 change (Treseder \& Allen, 2002; Johnson, 2009). For example, Blanke et al. (2012) found that

75 for plants grown in soils co-limited by $\mathrm{N}$ and $\mathrm{P}, \mathrm{P}$ addition decreased colonization while $\mathrm{N}$

76 addition increased colonization.

77 To our knowledge, all previous experimental field studies of AMF-plant responses to

78 climate change were performed at a single site. However, important factors such as soil

79 characteristics and plant community composition often have high local variability. To extrapolate

80 site-specific results to a regional scale requires understanding the roles of both regional and local

81 controls on AMF and plant responses. To this end, we used a manipulative climate change

82 experiment embedded within a Mediterranean climate gradient in the Pacific Northwest (Kottek

83 et al., 2006) to determine the underlying direct and indirect effects of increased temperatures on

$84 \mathrm{AMF}$ and their plant hosts in Mediterranean climates. Mediterranean ecosystems contain a large

85 percentage of global biodiversity of terrestrial plants $(20 \%)$ in proportion to their total terrestrial

86 area (5\%) (Cowling et al., 1996). They are also among the most sensitive biomes to global

87 climate change in terms of biodiversity (Sala et al., 2000).

88 We hypothesized that much of the effect of temperature on AMF colonization, as well as

89 the host plants' nutrient composition and biomass, would be mediated through interactions with

90 vegetation dynamics and the availability of soil water and nutrients. We were also interested in

91 whether these effects were regionally consistent along a gradient of increasing summer drought

92 stress.

93

94 Materials and Methods

95

96 Site Descriptions 
We studied three prairie sites along a $520 \mathrm{~km}$ latitudinal climate gradient in the inland

98 valleys of the Pacific Northwest (Table 1). The southernmost site is in southwestern Oregon near

99 the town of Selma, the central site is in central-western Oregon near the city of Eugene, and the

100 northernmost site is in central-western Washington near the town of Tenino. The sites occur

101 along a gradient of increasing severity of Mediterranean climate from north to south (Table 1).

102 The southern site has the most extreme seasonal variation, experiencing the wettest, coolest

103 winters and driest, warmest summers. The central and northern sites have comparatively milder

104 winters and summers in terms of rainfall and temperature, with the central site having warmer

105 average summer and winter temperatures than the northern site. Global climate change models

106 for the Pacific Northwest predict an increase in average annual temperatures of $+3.0^{\circ} \mathrm{C}$ by 2080

107 (range $+1.5^{\circ} \mathrm{C}$ to over $+5.8^{\circ} \mathrm{C}$ ) (Mote \& Salathe, 2010). While average annual precipitation

108 projections are highly variable among different emission scenarios and models (range $-10 \%$ to

$109+20 \%$ by 2080 ), across models there is a consistent prediction of warmer, wetter winters

110 (precipitation range $+8 \%$ to $+42 \%$ ) and hotter, dryer summers (precipitation range $-14 \%$ to -

111 40\%) (Mote \& Salathe, 2010).

112 As is typical for a study spanning a large region, each site has a different soil type. The

113 southern site is a loamy Mollisol (coarse-loamy, mixed, superactive, mesic Cumulic

114 Haploxeroll), the central site is a silty-clay loam Mollisol (very-fine, smetitic, mesic Vertic

115 Haploxeroll), and the northern site is a gravelly sandy loam Andisol (sandy-skeletal, amorphic-

116 over-isotic, mesic Typic Melanoxerand). The southern site has a circumneutral $\mathrm{pH}$, and the

117 central and northern sites are mildly acidic (Table 1). These differences in soil characteristics

118 translate into large differences in nutrient availability, with the southern site having much greater

$119 \mathrm{~N}$ and $\mathrm{P}$ availability (Supporting Information Fig. S1) and a greater N:P ratio (Table 1). The

120 central site had moderately greater $\mathrm{N}$ and $\mathrm{P}$ availability and a lower $\mathrm{N}: \mathrm{P}$ ratio than the northern

121 site.

122

123 Experimental Design

124 In accordance with the predicted climate change for the Pacific Northwest (as stated

125 above), we employed a fully factorial design of $+3^{\circ} \mathrm{C}$ above ambient canopy temperature, $20 \%$

126 increased precipitation, both increased temperature and precipitation, and ambient controls, with

127 five replicate $3 \mathrm{~m}$ diameter plots of each treatment at each site. Heating treatments used infrared 
128 heaters (Kalglo heaters model HS 2420, Kalglo Electronics Co., Inc.) controlled by a dimmer

129 system (Kimball, 2005; Kimball et al., 2008). Dummy heaters were installed in non-heated plots

130 to account for potential shading effects. The plots were isolated from the surrounding soil by

131 burying an aluminum barrier to $40 \mathrm{~cm}$ depth, or to the depth of major obstruction. The

132 precipitation treatments have resulted in only minor effects on all response variables for which it

133 has been examined, including a wide array of plant responses (Pfeifer-Meister et al., 2013, and

134 unpublished data). For this reason and series of other logistical constraints, we considered only

135 the heated and control treatments in our present study.

136 Plots at each site were treated in 2009 with one or two applications of the herbicide

137 glyphosate (spring and fall) followed by thatch removal and seeding with an identical mix of 33

138 annual (12 forbs, 1 grass) and perennial (15 forbs, 5 grasses) native prairie species within each

139 plot. During the same period of the initial planting, we started the heating and precipitation

140 treatments. For each site, we collected seed from the nearest local population of each species, or

141 purchased seed from a native plant nursery that used first-generation plants from the nearest seed

142 source. During the 2010 growing season, the most aggressive exotic species were weeded, but

143 natural succession was allowed to occur afterwards resulting in a mix of species that were either

144 intentionally seeded, came from the seed bank, or dispersed into the plots.

145 In the 2011 growing season, we selected four native forbs for assessment of climate

146 effects on AMF associations. Graminoid species were not assessed because no common species

147 grew within all plots across all sites. The selected focal species were: Achillea millefolium L.,

148 Asteraceae (perennial); Eriophyllum lanatum (Pursh) Forbes, Asteraceae (perennial); Plectritis

149 congesta (Lindl.) DC., Valerianaceae (annual); and Prunella vulgaris L. ssp. lanceolata (W.

150 Bartram) Hultén., Lamiaceae (perennial).

151

152 Plot Measures

153 Soil temperature and volumetric water content were continuously monitored in the center

154 of each plot with Campbell Scientific, Inc., Model 107 Temperature Probes and Campbell

155 Scientific, Inc., CS616 Water Content Reflectometers, respectively. The average plot values for

156 the one-month period prior to harvesting were used for analysis (Fig. 1). We considered other

157 time frames, but this time period had the strongest correlation with AMF colonization. To enable

158 comparison of soil water availability across sites, volumetric water content was converted to 
159 matric potential using site-specific values of soil texture and organic matter content (Saxton \& 160 Rawls, 2006).

161 Soil N and P availability were determined with anion and cation exchange probes

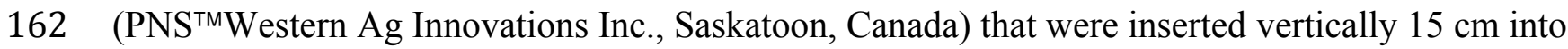

163 the ground from April-July, 2011. $\mathrm{NH}_{4}{ }^{+}-\mathrm{N}$ and $\mathrm{NO}_{3}{ }^{-}-\mathrm{N}$ were combined into a single value for

164 total inorganic $\mathrm{N}$, although the value was dominated by $\mathrm{NO}_{3}-\mathrm{N}$.

165 Belowground net primary productivity (NPP) was measured using the root in-growth

166 core method (Lauenroth, 2000) with $5 \mathrm{~cm}$-diameter by $20 \mathrm{~cm}$-depth cores. Aboveground NPP

167 was estimated by destructive harvesting at peak standing biomass of a $0.30 \mathrm{~m}^{2}$ area within each

168 plot. All vegetation was dried to a constant mass at $60^{\circ} \mathrm{C}$ before weighing. Aboveground

169 biomass was also separated into forb and grass NPP. Total cover of all species was averaged per

170 plot by using the point-intercept method (Jonasson, 1983) with two $1 \mathrm{~m}^{2}$ quadrats of 25 points

171 each. Presence/absence was determined for all species that were not hit by a pin in a plot, and

172 they were assigned a cover of $0.4 \%$. We calculated plant species diversity using the average of

173 the two quadrats per plot using Simpson's Diversity Index (1/D).

174

175 Individual Plant Measures

176 We harvested three individuals of each focal plant species within each heated and control

177 plot. We had to limit the number of individuals and limit the harvest to one annual collection

178 because the plants were relatively large, and uprooting them caused disturbance to the rest of the

179 plots and other experiments. Plants were collected at peak flowering to maintain consistency in

180 phenology across the treatments and sites; thus, the annual species was collected approximately

181 one month before the perennial species (Fig. 1). We weighed aboveground plant material after

182 drying at $60^{\circ} \mathrm{C}$ for 48 hours. Using subsamples of ground and dried material, we determined total

183 P by performing a hydrogen peroxide-sulfuric acid digest (Haynes, 1980) using a Lachat BD-46

184 Digester (Hach Company, Loveland, $\mathrm{CO}$ ) and then measuring phosphate with the vanadate-

185 molybdate colorimetric method (Motsara \& Roy, 2008). Total $\mathrm{C}$ and $\mathrm{N}$ content were measured

186 with a Costech Elemental Analyzer ECS 4010 (Costech Analytical Technologies Inc., Valencia,

187 California, USA).

188 Due to the small size of the annual species, $P$. congesta, we pooled individuals across

189 plots within a treatment in order to obtain enough plant material to measure $P$ at all of the sites, 
190 and $\mathrm{N}$ at the northern site, resulting in a sample size of one per treatment. Thus, we do not report

191 pair-wise comparisons between treatments on plant $\mathrm{P}$ or $\mathrm{N}$ for this species for these sites.

192

193 Mycorrhizal Measures

194 The percentage of plant root colonized by arbuscular mycorrhizas (i.e., AMF

195 colonization) is a measure of AMF abundance (Vierheilig et al., 2005). To quantify AMF

196 colonization, a subsample of roots from each plant was taken and boiled in a 5\% Sheaffer®

197 black ink-to-white vinegar solution for 10 minutes after being cleared with $10 \% \mathrm{KOH}$

198 (Vierheilig et al., 1998). Using the grid-intersect method (McGonigle et al., 1990), we calculated

199 the percentage of arbuscules, vesicles, and total root colonization separately by counting the

200 presence or absence of arbuscules and/or vesicles connected by characteristic AMF hyphae for

201 each millimeter of root segment.

202 To compare the AMF community composition across treatments and sites, we performed

203 an initial trial run with one of our focal plant species, Eriophyllum lanatum. DNA was extracted

204 using the PowerPlant ${ }^{\circledR}$ DNA isolation kit, and purified with Zymo DNA Clean \&

205 Concentrator ${ }^{\mathrm{TM}}$. AMF DNA extracted from the plant roots was amplified by PCR using the

206 AMF-specific rDNA primers AML2 (Lee et al., 2008) and NS31 (Simon et al., 1992). The

207 resulting amplicons were sequenced using an Illumina HiSeq 2000 sequencer (Genomics Core

208 Facility, University of Oregon). Preliminary sequence data were analyzed using MOTHUR

209 (Schloss et al., 2009). Unfortunately, less than 1\% (92/14,000) of the resulting sequences were

210 identified as AMF using BLAST (the remaining were plant DNA sequences), and further

211 community analyses were not performed. A list of species identified can be found in Supporting

212 Information Table S1.

213

214 Greenhouse Study

215 Because of large differences in nutrient availability, $\mathrm{pH}$, and texture among sites (Table

216 1), we performed a greenhouse experiment to determine the effect of soil type on AMF

217 colonization. Ten previously germinated seedlings of each species were planted in flats

218 containing soil outside the plots from each site. Plants grew for eight weeks in a climate-

219 controlled greenhouse at a constant $25^{\circ} \mathrm{C}$ under natural light (approximately 12-14 hours a day)

220 and were watered as needed to remain above wilting point. After eight weeks, we harvested all 
221 plants, measured the dry weight of aboveground biomass, and used the same protocol described

222 above to quantify the AMF colonization for each plant.

223

224

Data Analysis of the Greenhouse and Field Experiment (ANOVAs)

225

For the greenhouse experiment, we used two-way ANOVAs (species, soil type) to test for

226 differences in AMF colonization and aboveground plant biomass. For the field experiment, we

227 used three-way ANOVAs (species, site, and treatment) to test for differences in AMF colonization, aboveground plant biomass, soil $\mathrm{N}$ availability, soil $\mathrm{P}$ availability, the ratio of soil $\mathrm{N}: \mathrm{P}$ availability, plant $\mathrm{N}$ content, plant $\mathrm{P}$ content, and the plant N:P ratio. Although we measured arbuscule, vesicle, and total colonization separately, arbuscule colonization never differed from total colonization, and vesicle colonization was minimal. Thus, we only report total colonization for both greenhouse and field experiments. Soil and plant nutrient analyses can be found in

233 Supporting Information Tables S7-S12.

For all analyses of the greenhouse and field experiments, we performed separate ANOVAs on each species when there was a significant species interaction with any of the other main effects. Post-hoc comparisons were performed using Tukey's HSD. For both greenhouse and field data sets, we used an arcsine-square root transformation to normalize the AMF colonization data, and a logarithm transformation to normalize the plant biomass and nutrient 239 data.

\section{Structural Equation Models of the Field Experiment}

242 We used structural equation modeling (SEM) (Grace 2006) to examine the effect of 243 experimental warming on AMF colonization, and how it may be mediated by soil water 244 availability, soil nutrient availability, and plot vegetation. We also assessed how interactions among these factors affected host plant nutrient content and biomass.

The greenhouse data suggested that soil type had a significant effect on AMF

247 colonization, and we hypothesized this was due to differences in soil nutrient availability of P 248 and/or N. However, the ratio of N:P has been suggested to be a more powerful predictor of AMF 249 responses than availability of either nutrient alone (Johnson, 2009). Therefore, we developed 250 three a priori SEMs to determine whether $\mathrm{N}, \mathrm{P}$, or the ratio of $\mathrm{N}: \mathrm{P}$ had a larger effect in 
251 mediating AMF responses to temperature. Each model was identical except for the specific

252 variables used to represent soil nutrients or plant nutrients in Fig. 2.

$253 \quad$ Net Primary Productivity (NPP) and plant species diversity have been shown to affect

254 AMF (Vandenkoornhuyse et al., 2003; Johnson et al., 2004). We tested our models using above-

255 and belowground NPP, the ratio of above:below NPP, grass and forb NPP, the ratio of grass:forb

256 NPP, and plant species diversity, using each separately as the vegetation variable in Fig. 2. Plant

257 diversity had the greatest effect on AMF colonization, so we dropped the NPP measures from

258 subsequent analyses to simplify our models.

259 The maximum likelihood method was used for model evaluation and to estimate the

260 standardized path coefficients (Grace, 2006). For all analyses, we present only models that had

261 good model fit as estimated by Pearson's chi-square goodness of fit $\left(\chi^{2}\right)(\mathrm{P}>0.05$ indicates good

262 model fit), the Bentler Comparative Fit Index (CFI) $(<0.90$ indicates good model fit), and the

263 Root Mean Square Error of Approximation (RMSEA) $(<0.05$ indicates good model fit) (Bentler,

264 1990; Grace, 2006). For models with good fit, we present only path coefficients that were

265 significant at $P<0.10$. All SEM analyses were performed using Amos 20.0 SEM software

266 (SPSS Inc., Chicago IL, USA).

267

268

Results

269

270

271

Greenhouse Experiment

$2720.0001]$ and among the four species $[F(3,103)=11.7, P<0.001]$, and the effect of soil type

273 marginally depended on species $[F(6,103)=1.9, P=0.09$, Fig. 3a) $]$. For the three perennial

274 species, we consistently found that plants grown in soil from the southern site had the lowest

275 colonization $(P<0.001)$, whereas plants grown in soil from the central and northern site did not

276 differ. The annual species, $P$. congesta, had the greatest colonization when grown in soil from

277 the central site $(P=0.006)$.

278 Aboveground plant biomass differed by soil type $[F(2,103)=187.6, P<0.001]$ and

279 among the four species $[F(3,103)=97.2, P<0.001]$, and the effect of soil type depended on

280 species $[F(6,103)=23.9, P<0.001]$. Despite the significant interaction, we found a consistent

281 trend among the three perennial species, which were largest when grown in soil from the 
282 southern site $(P<0.001$, Fig. 3b), whereas plants grown in the central and northern site soil did

283 not differ in size. The annual species, P. congesta, was largest when grown in southern site soil, 284 intermediate in the central site soil, and smallest in the northern site soil $(P<0.000)$.

285

286

Field Experiment

287

Differences in AMF colonization among sites depended on species $[F(6,281)=4.4, P<$

288 0.001, Supporting Information Table S2]. Colonization did not differ among the sites for $A$. millefolium and $P$. vulgaris, but $E$. lanatum marginally had the greatest colonization in the southern site $(P<0.07)$, and $P$. congesta had the lowest colonization in the central site $(P=$ 0.01). Across all sites and species, heating consistently lowered colonization $[F(1,281)=17.8$, $292 \quad P<0.001$, Fig. 4a].

Differences in aboveground plant biomass among sites depended on species $[F(6,290)=$ 294 19.6, $P<0.001$, Supporting Information Table S3]. A. millefolium was largest at the central site $295(P<0.001)$ and E. lanatum and $P$. vulgaris were smallest at the northern site $(P \leq 0.05)$. $P$. 296 congesta was largest at the southern site $(P<0.001)$.

297 The effect of the heating treatment on plant biomass depended on both site $[F(2,290)=$ $2984.6, P=0.01]$ and species $[F(3,290)=3.5, P=0.02]$. Heating decreased the size of $A$.

299 millefolium plants at the southern site $(P=0.001)$, increased the size of $P$. vulgaris plants at the 300 northern site $(P=0.001)$, and increased the size of $P$. congesta plants in the southern and 301 northern sites $(P \leq 0.042)$. E. lanatum size was not affected by heating treatments, although it 302 trended toward larger plants in the heating treatments across sites (Fig. 4b).

303

304

305

\section{Structural Equation Models}

306

To test the three a priori SEMs (Fig. 2), we used data across all sites and species (for a table of means and Pearson's correlations of the data, see Supporting Information Tables S4 and $\mathrm{S} 5)$. Both the $\mathrm{P}$ and the $\mathrm{N}: \mathrm{P}$ ratio model had good model fit (P SEM: $\chi^{2}=0.081, P=0.78$, $C F I=1.0, R M S E A<0.0001 ; \mathrm{N}: \mathrm{P}$ ratio SEM: $\left.\chi^{2}=0.002, P=0.96, C F I=1.0, R M S E A<0.0001\right)$, while the $\mathrm{N}$ model had poor model fit $\left(\chi^{2}=26.3, P<0.0001, C F I=0.96, R M S E A=0.284\right)$ and was dropped from further consideration. Both the $\mathrm{P}$ and $\mathrm{N}: \mathrm{P}$ ratio models had similar magnitudes and directions of the path coefficients. However, the plant $\mathrm{N}: \mathrm{P}$ ratios suggested $\mathrm{N}$ limitation or $\mathrm{N}$ and $\mathrm{P}$ co-limitation (Supporting Information Fig. S2c), as plants with a ratio $<10$ and $>20$ are 
313 considered to be $\mathrm{N}$ limited and P limited, respectfully (Güsewell, 2004). Thus, we chose the N:P 314 model (Fig. 5) for further interpretation (see Supporting Information Fig. S3 for P only model 315 results).

316 We also examined the consistency of the N:P SEM model among each species and each 317 site separately. Models for individual species showed similar patterns as the model using all 318 species, but had poor model fit, presumably due to the lower sample size $(\mathrm{N}<100)$, and we do not consider them further. Similarly, models that included data from each site separately had poor model fit, except for the model that included data from only the southern site $\left(\chi^{2}=0.76, P\right.$ $=0.38, C F I=1.0, R M S E A<0.0001)$. We were particularly interested in the SEM of the southern 322 site because this site has much higher nutrient availability (Table 1), and the heated plots were beginning to experience extreme drought conditions at the time of plant collection (Fig. 1).

The overall SEM was fairly successful in explaining the variance in soil N:P $\left(r^{2}=0.26\right)$, plant diversity $\left(r^{2}=0.45\right)$, and plant biomass $\left(r^{2}=0.49\right)$, but less successful in explaining the plant N:P ratio $\left(r^{2}=0.19\right)$ and AMF abundance $\left(r^{2}=0.08\right)$. Although all but three predicted path coefficients from the a priori model (Fig. 2) were significant (Fig. 5), we focus only on the direct and indirect effects on AMF colonization and plant biomass to simplify our presentation.

While temperature had a moderately strong direct negative effect on AMF colonization, as we hypothesized (Fig. 2), there were also many indirect effects of temperature on AMF colonization that were mediated by soil water availability, soil N:P, and plant diversity (Fig. 5). Soil N:P and plant diversity had moderate direct positive effects on AMF colonization. Soil water availability did not have a significant direct effect on AMF colonization, although it did

334 have considerable indirect effects which were mediated by both soil N:P and plant diversity.

335 Because some indirect pathways were positive and some were negative, the total indirect effect 336 of temperature on AMF colonization as mediated by other variables was negligible (Table 2).

337 Thus, the total effect of temperature on AMF colonization was predominately the direct negative 338 effect.

Similarly, there were many indirect effects of temperature on the host plant biomass, which were mediated by soil water availability, soil N:P, plant diversity, AMF colonization, and plant N:P ratio. However, similar to AMF colonization, the various negative and positive indirect

342 effects canceled each other out, and the total effect of temperature on plant biomass was largely a 343 direct effect (Table 2). AMF colonization had a modest positive effect on plant biomass, which 
344 was also driven by direct, rather than indirect effects (Table 2, Fig. 6). Contrary to our

345 expectations, AMF colonization did not affect plant N:P ratios, though plant N:P ratios had a 346 strong negative effect on plant biomass.

347 Even though the southern site SEM had fewer significant pathways than the overall SEM, 348 and the path coefficients were different in magnitude (and occasionally direction), the general 349 outcomes were very similar to the overall SEM (Fig. 6, Supporting Information Fig. S4). The 350 effect of temperature on AMF colonization was still largely a direct negative effect, as indirect 351 effects canceled out. The effect of temperature on plant biomass was also predominately a 352 positive direct effect (Fig. 6, Supporting Information Table S6).

353 The southern site SEM was different in that there was a stronger negative effect of 354 temperature on AMF colonization, and AMF colonization had a much stronger positive effect on 355 plant biomass. The total explained variance of AMF colonization was higher for the southern site 356 than the overall SEM (19\% compared to 8\%; Supporting Information Fig. S4 and Fig. 5, 357 respectively). The total effect of temperature on plant biomass was, however, identical to the 358 overall SEM (0.39, Fig. 6), and the total explained variance in plant biomass was very similar 359 (44\% compared to 49\%, Supporting Information Fig. S4 and Fig. 5, respectively).

\section{Discussion}

\section{Site-Level Effects: Comparing Greenhouse and Field Experiments}

In the greenhouse experiment, which was used to isolate the effects of soil type on AMF colonization and host plant response, we found the expected pattern of higher colonization in the soils with lower nutrient availability (Mosse \& Phillips, 1971; Smith \& Read, 2008). Even though colonization was higher in the central and northern site soils, plants were consistently smaller, suggesting that increased colonization did not fully compensate for the large differences in soil nutrient availability between the southern site and the other two sites. among sites. Although there was a general trend for plants at the northern site to be smaller,

372 differences in plant size between the southern and central site were not consistent among species.

373 These results suggest that the effects of climate may overwhelm the effect of soil type and 
374 nutrient availability on AMF colonization and plant biomass, although we cannot exclude the

375 possibility that other site-level factors were important.

376

377 Heating Effects

378 The most intriguing result from the field experiment was the consistent decrease in AMF

379 colonization in the heating treatment, in contrast to the positive effects reported from the

380 majority of similar warming studies (Compant et al., 2010). There also was a general trend of

381 increased aboveground biomass in the heating treatments, which is consistent with treatment

382 effects on 12 different species from a related experiment that used the same climate manipulation

383 (Pfeifer-Meister et al., 2013) and aboveground NPP collected at the plot level (data not shown).

384 We used SEM to test our hypothesis that the effect of temperature on AMF and their

385 plant hosts would be mediated by indirect interactions with soil water availability, soil nutrients,

386 and plant species diversity. However, because of both negative and positive interactions, these

387 indirect effects canceled out, and the total effect of temperature was driven by the direct effects

388 (Fig. 6, Table 2). We also demonstrated that this result was regionally consistent across the

389 Mediterranean climate gradient represented by our three sites, despite the local site effects of soil

390 type demonstrated in the greenhouse experiment. We are confident this result was not driven

391 primarily by innate site differences because the southern site SEM had similar effects of

392 temperature, despite some differences in causal pathways (Supporting Information Fig. S4).

393 Moreover, the ANOVA results from the field experiment support the finding of a negative

394 heating effect across sites and species (Fig. 5).

395 However, our analysis was limited to a single growing season after less than two years of

396 heating. Over time, the effect of increasing temperature could make these indirect effects

397 stronger or alter the balance among them. Additionally, 2011 was a La Niña year with greater

398 spring precipitation than in other years. Moreover, the Pacific Northwest and Mediterranean

399 regions globally are predicted to experience increasingly severe summer drought and heavier

400 winter rains over the $21^{\text {st }}$ century (Mote \& Salathe, 2010; Ruffault et al., 2012). Thus, indirect

401 effects mediated by soil water moisture could become more prominent in the future. Given these

402 considerations, we examine the direct and indirect pathways in some detail below.

403

404 Indirect Effects 
Deconstructing the total effects into indirect and direct effects helped reveal possible

406

407

408

409

410

411

412

413

414

415

416

417

418

419

420

421

422

423

424

425

426

427

428

429

430

431

432

433

434

435

mechanisms that could be responsible for the results we found, and we discuss a few examples of these complicated indirect effects as follows.

The total effect of temperature on soil N:P was nearly neutral because the direct effect was negative (-0.42) and the indirect effect was positive (+0.32) (Table 2 and Fig. 5). It seems, however, that the negative direct effect was driven by innate site difference in soil type (not the heating treatments). This negative relationship was clearly shown in a scatter plot of soil N:P vs. temperature (data not shown), where the soil N:P ratio was much higher in the southern site than the more northern sites, but temperatures during this time period were higher in the northern site than southern site (Supporting Information Table S4).

The positive indirect effect of soil temperature on soil N:P was driven by the negative effect of soil temperature on soil water availability, which in turn had a strong negative effect on soil N:P (resulting in a net positive effect). This positive effect agrees with our nutrient data (Table 1), where we saw an increase in soil N:P in the heating treatments in two of the three sites. Additionally, in the southern only SEM there was only a positive effect of soil temperature on soil N:P (Supporting Information Fig. S4).

Assuming that the negative direct effect of soil temperature on soil N:P was mainly driven by innate differences in soil type among the sites, our results suggest that increasing soil temperatures caused a shift toward P limitation due to a decrease in soil water availability. This may reflect the much greater mobility of nitrate (the predominant form of inorganic $\mathrm{N}$ in our sites) than P in soils. Increasing soil N:P had a moderate direct positive effect on AMF colonization, and it has been shown that plants in P-limited soils tend to have increased colonization and produce more exudates known to attract AMF (Ostertag, 2001; Yoneyama et al., 2012). The positive effect of warming on AMF colonization that most other studies have found could have been due to increased P limitation mediated by soil water availability (Rillig et al., 2002; Staddon et al., 2003). The relative limitation of $\mathrm{P}$ and $\mathrm{N}$ has been previously suggested as an important driver of AMF responses (Johnson, 2009). Testing all three of the a priori SEMs revealed that the N:P ratio was a better predictor of AMF colonization than the availability of soil $\mathrm{N}$ or $\mathrm{P}$ alone.

34 Although it makes sense that increasing soil P limitation would increase AMF colonization, the positive direct effect $(+0.19)$ was diminished by the negative indirect effect $(-$ 
436 0.12) mediated via plant diversity. Consistent with previous studies of the effect of plant 437 diversity on AMF (Vandenkoornhuyse et al., 2003; Johnson et al., 2004), plant diversity had a 438 positive effect on AMF colonization $(+0.18)$. Because increasing soil $\mathrm{N}: \mathrm{P}$ had a strong negative 439 effect on plant diversity (-0.66), this indirect effect of soil N:P on AMF colonization was 440 negative.

441 We found that plant species diversity was a better predictor of AMF colonization than 442 various measures of net primary productivity (see Plot Measures). While it has been suggested 443 that increased productively should directly affect AMF by increasing belowground $\mathrm{C}$ allocation 444 (Pendall et al., 2004), it has also been shown that nutrient and $\mathrm{C}$ allocation are not shared equally 445 among the plant and fungal symbionts within a community (Klironomos, 2003; van der Heijden 446 et al., 2003; Leake et al., 2004). Higher plant diversity may provide an improved root network 447 that accommodates both higher colonization and AMF diversity (van der Heijden et al., 2003; 448 Leake et al., 2004).

\section{Direct Effects}

The direct negative effect of temperature on AMF colonization could have been a 452 physiological response of the AMF (Koltai \& Kapulnik, 2010). However, the total explained 453 variance in AMF colonization for both the overall and southern only SEM was small (8\% and $45418 \%$, respectively), and the direct effect may have been mediated by something we did not 455 measure. Increased temperatures have been shown to decrease extraradical hyphae, presumably 456 due to higher decomposition and turnover rates (Rillig et al., 2002; Rillig, 2004; Wilson et al., 457 2009). Because extraradical and internal root colonization has repeatedly been shown to be 458 positively correlated (Wilson et al., 2009; Barto et al., 2010; van Diepen et al., 2010), we predict 459 we would have observed a decrease in extraradical hyphae as well, had it been measured. A 460 decrease in extraradical hyphae drastically decreases glomalin production, a glycoprotein that 461 has been shown to increase soil stability (Rillig, 2004). Decreased AMF colonization could have 462 serious consequences to overall ecosystem functions by destabilizing soil aggregates (Wilson et 463 al., 2009).

464 We saw a positive total effect of temperature on plant biomass in both the overall and 465 southern SEM, which was also primarily driven by the direct effect. Likewise, we found a 466 modest positive total effect, driven primarily from the direct effect, of AMF colonization on 
467 plant biomass in the overall SEM (Fig. 6). The same was true for the southern site SEM, but the 468 effect of AMF colonization on plant biomass was much stronger (Supporting Information Fig.

469 S4). Although the total effect of heating on biomass was positive, over time the indirect negative 470 effect on plant biomass (via the negative temperature effect on AMF colonization) could dampen 471 the total positive effect of temperature on plant biomass, in addition to other ecosystem 472 consequences.

473

474 AMF Community Data

475 AMF colonization did not have any effect on plant N:P ratios (Fig. 5 and Fig. S4) or plant 476 P content (Supporting Information Fig. S3). Although AMF are well known for enhancing P 477 uptake, it has been shown that enhanced uptake via the AMF symbiont is not necessarily 478 correlated with the degree of AMF colonization or the P content in the plant (Smith et al., 2004). 479 However, plant species diversity had a relatively strong effect on plant N:P (negative effect in 480 the southern-only SEM and positive effect in the overall SEM), which could have been mediated 481 by the community of AMF, rather than the overall colonization (van der Heijden et al., 1998; 482 Klironomos et al., 2000; van der Heijden et al., 2003).

Although our community data are limited, we do have evidence that there was a diverse 484 community of AMF across and within the sites. Our community data set (from one host plant 485 species, E. lanatum) spans most major families of the Glomeromycota (Supporting Information Fig. S5, Table S1). It would be interesting to further investigate the links between plant species diversity, AMF community, and plant nutrient uptake under climate change.

488

\section{Conclusions}

We found that the direct effect of increasing temperatures caused a decrease in AMF colonization, and this appeared to be regionally consistent across the Mediterranean climate 492 gradient. A suite of complicated indirect effects mediated this response, although these effects 493 canceled out due to both positive and negative effects. However, because of the fine balance of 494 indirect effects, this region could potentially be quite sensitive to climate change. Over time, a 495 shift in the relative strengths of different indirect effects could either exacerbate or mitigate the 496 negative direct effect of temperature on AMF colonization. Furthermore, we cannot rule out the 497 possibility that the direct effect may have been mediated by other variables we did not measure, 
498 such as glomalin secretion and related effects on soil stability. AMF colonization appears to be 499 most important for plant biomass production in the southern site, the most extreme site in terms 500 of Mediterranean seasonality. Thus, should ecosystems in Mediterranean climates experience

501 even more intense droughts and heavier rains as predicted under many climate change scenarios,

502 a subsequent decrease in AMF colonization could have substantial consequences for plant 503 communities and ecosystem function.

504 To our knowledge, this is the first manipulative climate change study to examine the 505 regional response of AMF interactions. Interestingly, our results challenge the conventional view 506 that AMF respond positively to increased temperature. Many previous studies, however, were 507 either performed in a greenhouse or at a single site, potentially limiting the generality of their 508 results. Our research highlights how multi-site experiments at the regional level are needed to 509 make reliable generalizations about the response of AMF-plant interactions to climate change. 510

\section{Acknowledgements}

512 Much appreciation goes out to The Nature Conservancy, The Center for Natural Lands 513 Management, and The Siskiyou Field Institute for providing the location of the field sites.

514 Special thanks to Maya Goklany for her help with the analysis, Dr. Timothy Tomaszewski and 515 Lorien Reynolds for providing essential data, and Roo Vandergrift for assistance with laboratory 516 work. 


\section{References}

519 Araújo MB, Luoto M. 2007. The importance of biotic interactions for modeling species

520 distributions under climate change. Global Ecology and Biogeography 16: 743-753.

521

522 Bago B, Pfeffer PE, Shachar-Hill Y. 2000. Carbon metabolism and transport in arbuscular 523 mycorrhizas. Plant Physiology 124: 949-958.

524

525 Baon JB, Smith SE, Alston AM. 1994. Phosphorus uptake and growth of barley as affected by

526 soil temperature and mycorrhizal infection." Journal of Plant Nutrition 17: 479-492.

527

528 Barto EK, Alt F, Oelmann Y, Wilcke W, Rillig MC. 2010. Contributions of biotic and abiotic 529 factors to soil aggregation across a land use gradient. Soil Biology and Biochemistry 42: 23165302324.

531

532

Bentler PM 1990. Comparative fit indexes in structural models. Psychological Bulletin, Vol

533 107: 238-246

534

535

Blanke V, Bassin S, Volk M, Fuhrer J. 2012. Nitrogen deposition effects on subalpine

536 grassland: the role of nutrient limitations and changes in mycorrhizal abundance. Acta

537 Oecologica 45: 57-65.

538

539

Compant S, van der Heijden MGA, Sessitsch A. 2010. Climate change effects on beneficial

540 plant-microorganism interactions. FEMS Microbiology Ecology 73: 197-214.

541

542

Cowling RM, Rundel PW, Lamont BB, Kalin-Arroyo M, Arianoutsou M. 1996. Plant

543 diversity in Mediterranean-climate regions. Trends in Ecology \& Evolution 11: 362-366.

544

Davies FT, Olalde-Portugal V, Aguilera-Gomez L, Alvarado MJ, Ferrera-Cerrato RC,

546 Boutton TW. 2002. Alleviation of drought stress of chile ancho pepper Capsicum annuum L. cv.

547 San Luis) with arbuscular mycorrhiza indigenous to Mexico. Scientia Horticulturae 92: $347-$ 548359. 
550 Drigo B, Kowalchuk GA, Veen JA. 2008. Climate change goes underground: Effects of

551 elevated atmospheric $\mathrm{CO}_{2}$ on microbial community structure and activities in the rhizosphere.

552 Biology and Fertility of Soils 44: 667-679.

553

554 Fitter AH, Heinemeyer A, Staddon PL. 2000. The impact of elevated $\mathrm{CO}_{2}$ and global climate

555 change on arbuscular mycorrhizas: A mycocentric approach. New Phytologist 147: 179-187.

557 Grace JB. 2006. Structural Equation Modeling and Natural Systems. Cambridge, UK:

558 Cambridge University Press.

559

560 Graham JH, Leonard RT, Menge JA. 1982. Interaction of light intensity and soil temperature

561 with phosphorus inhibition of vesicular-arbuscular mycorrhiza formation. New Phytologist 91:

$562683-690$.

563

564 Güsewell S. 2004. N: P ratios in terrestrial plants: variation and functional significance. New 565 Phytologist 164: 243-266.

566

567 Haynes RJ. 1980. A comparison of two modified Kjeldahl digestion techniques for multi568 element plant analysis with conventional wet and dry ashing methods. Communications in Soil 569 Science \& Plant Analysis 11: 459-467.

570

571 Heinemeyer A, Ineson P, Ostle N, Fitter AH. 2006. Respiration of the external mycelium in

572 the arbuscular mycorrhizal symbiosis shows strong dependence on recent photosynthates and 573 acclimation to temperature. New Phytologist 171: 159-170.

574

575 Johnson D, Vandenkoornhuyse PJ, Leake JR, Gilbert L, Booth RE, Grime JP, Young

576 JPW, Read DJ. 2004. Plant communities affect arbuscular mycorrhizal fungal diversity and 577 community composition in grassland microcosms. New Phytologist 161: 503-515. 
579 Johnson NC. 2009. Resource stoichiometry elucidates the structure and function of arbuscular 580 mycorrhizas across scales. New Phytologist 185: 631-647.

581

582 Jonasson S. 1983. The point intercept method for non-destructive estimation of biomass.

583 Phytocoenologia 11: 385-388.

584

585

Kimball BA. 2005. Theory and performance of an infrared heater for ecosystem warming.

586 Global Change Biology 11: 2041-2056.

587

588

Kimbell BA, Conley MM, Wang S, Lin X, Lou C, Morgan J, Smith D. 2008. Infrared heater

589 arrays for warming ecosystem field plots. Global Change Biology 14: 309-320.

590

591

Kivlin SN, Hawkes CV, Treseder KK. 2011. Global diversity and distribution of arbuscular 592 mycorrhizal fungi. Soil Biology and Biochemistry 43: 2294-2303.

593

594

595 fungi. Ecology 84: 2292-2301.

596

597

Klironomos JN, McCune J, Hart M, Neville J. 2000. The influence of arbuscular mycorrhizae

598 on the relationship between plant diversity and productivity. Ecology Letters 3: 137-141.

599

600

Koltai H, Kapulnik Y. 2010. Arbuscular Mycorrhizas: Physiology and Function. New York, 601 NY: Springer.

602

603 Kottek M, Grieser J, Beck C, Rudolf B, Rubel F. 2006. World map of the Koppen-Geiger 604 climate classification updated. Meteorologische Zeitschrift 15: 259-263.

605

606 Lauenroth WK. 2000. Methods of estimating belowground net primary production. In: Sala OE, 607 ed. Methods in Ecosystem Science. Springer, 58-69. 
609 Leake J, Johnson D, Donnelly D, Muckle G, Boddy L, Read D. 2004. Networks of power and 610 influence: The role of mycorrhizal mycelium in controlling plant communities and

611 agroecosystem functioning. Canadian Journal of Botany 82: 1016-1045.

612

613 Lee J, Lee S, Young JPW. 2008. Improved PCR primers for the detection and identification of 614 arbuscular mycorrhizal fungi. FEMS Microbiology Ecology 65: 339-349.

615

616

McGonigle TP, Miller MH, Evans DG, Fairchild GL, Swan JA. 1990. A new method which gives an objective measure of colonization of roots by vesicular-arbuscular mycorrhizal Fungi.

618 New Phytologist 115: 495-501.

619

620

Miller RM, Jastrow JD, Reinhardt DR. 1995. External hyphal production of vesicular-

621 arbuscular mycorrhizal fungi in pasture and tallgrass prairie communities. Oecologia 103: 1762223.

623

624

Mosse B, Phillips JM. 1971. The influence of phosphate and other nutrients on the development 625 of vesicular-arbuscular mycorrhiza in culture. Journal of General Microbiology 69: 157-166.

626

627

Mote PW, Salathe EP. 2010. Future climate in the Pacific Northwest. Climatic Change 102: $62829-50$.

629

630

Motsara MR, Roy RN. 2008. Guide to Laboratory Establishment for Plant Nutrient Analysis. Rome, Italy: Food and Agriculture Organization of the United Nations.

632

Ostertag R. 2001. Effects of nitrogen and phosphorus availability on fine-root dynamics in Hawaiian montane forests. Ecology 82: 485-499.

635

Pendall E, Bridgham SD, Hanson PJ, Hungate B, Kicklighter DW, Johnson DW, Law BE, Luo Y, Megonigal JP, Olsrud M et al. 2004. Below-ground process responses to elevated $\mathrm{CO}_{2}$ and temperature: A discussion of observations, measurement methods, and models. New Phytologist 162: 311-322. 
640

641 Pfeifer-Meister L, Bridgham SD, Little CJ, Reynolds LL, Goklany ME, Johnson BR. 2013.

642 Pushing the limit: Experimental evidence of climate effects of plant range distributions. Ecology: 643 94: 2131-2137.

644

645 Rillig MC. 2004. Arbuscular mycorrhizae, glomalin, and soil aggregation. Canadian Journal of 646 Soil Science 84: 355-363.

647

648

Rillig MC, Wright SF, Shaw MR, Field CB. 2002. Artificial climate warming positively

649 affects arbuscular mycorrhizae but decreases soil aggregate water stability in an annual 650 grassland. Oikos 97: 52-58.

651

652

Ruffault J, Martin-St.Paul NK, Rambal S, Mouillot F. 2012. Differential regional responses 653 in drought length, intensity and timing to recent climate changes in a Mediterranean forested 654 ecosystem. Climatic Change 117: 103-117. 655

Ruiz-Lozano JM, Azcón R, Gomez M. 1995. Effects of arbuscular-mycorrhizal Glomus 657 species on drought tolerance: Physiological and nutritional plant responses. Applied and 658 Environmental Microbiology 61: 456-460.

659

660

Sala OE, Chapin FS, Armesto JJ, Berlow E, Bloomfield J, Dirzo R, Huber-Sanwald E, 661 Huenneke LF, Jackson RB, Kinzig A et al. 2000. Global biodiversity scenarios for the year 662 2100. Science 287: 1770-1774.

663

664 Saxton KE, Rawls WJ. 2006. Soil water characteristic estimates by texture and organic matter 665 for hydrologic solutions. Soil Science Society of America Journal 70: 1569-1578.

666

667 Schloss PD, Westcott SL, Ryabin T, Hall JR, Hartmann M, Hollister EB, Lesniewski RA, 668 Oakley BB, Parks DH, Robinson CJ. 2009. Introducing Mothur: Open-source, platform669 independent, community-supported software for describing and comparing microbial 670 communities. Applied and Environmental Microbiology 75: 7537-7541. 
671

672 Smith SE, Read DJ. 2008. Mycorrhizal Symbiosis. Cambridge, UK: Academic Press.

673

674 Smith SE, Smith FA, Jakobsen I. 2004. Functional diversity in arbuscular mycorrhizal (AM)

675 symbioses: The contribution of the mycorrhizal P uptake pathway is not correlated with

676 mycorrhizal responses in growth or total P uptake. New Phytologist 162: 511-524.

677

678

IPCC. 2007. Solomon S, Qin D, Manning M, Chen Z, Marquis M, Averyt KB, Tignor M, Miller

679

HL, eds. 2007. Climate Change 2007: The Physical Science Basis. Contribution of Working

680

Group I to the Fourth Assessment Report of the Intergovernmental Panel on Climate Change,

681

UK \& New York, NY, USA: Cambridge University Press.

682

683 Simon L, Lalonde M, Bruns TD. 1992. Specific ampliflication of $18 \mathrm{~S}$ fungal ribosomal genes 684 from vesicular-arbuscular endomycorrhizal fungi colonising roots. Applied and Environmental 685 Microbiology 58: 291-295

686

687

Staddon PL, Gregersen R, Jakobsen I. 2004. The response of two Glomus mycorrhizal fungi 688 and a fine endophyte to elevated atmospheric $\mathrm{CO}_{2}$, soil warming and drought. Global Change 689 Biology 10: 1909-1921.

690

691

Staddon PL, Thompson K, Jakobsen I, Grime JP, Askew AP, Fitter AH. 2003. Mycorrhizal

692 fungal abundance is affected by long-term climatic manipulations in the field. Global Change 693 Biology 9: 186-194.

694

Treseder KK, Allen MF. 2002. Direct nitrogen and phosphorus limitation of arbuscular 696 mycorrhizal fungi: A model and field test. New Phytologist 155: 507-515.

697

698

van der Heijden MGA, Wiemken A, Sanders IR. 2003. Different arbuscular mycorrhizal fungi 699 alter coexistence and resource distribution between co-occurring plant. New Phytologist 157: 700 569-578. 
70

703

704

705

706

707

708

709

710

711

712

713

714

715

716

717

718

719

720

721

722

723

724

725

726 $727 \quad 1197-1207$

728

729

730

731

732 683-695. 3085-3095.

van der Heijden MGA, Klironomos JN, Ursic M, Moutoglis P, Streitwolf-Engel R, Boller T, Wiemken A, Sanders IR. 1998. Mycorrhizal fungal diversity determines plant biodiversity, ecosystem variability and productivity. Geol. Soc. Am. Bull 100: 912-927.

van Diepen LTA, Lilleskov EA, Pregitzer KS, Miller RM. 2010. Simulated nitrogen deposition causes a decline of intra-and extraradical abundance of arbuscular mycorrhizal fungi and changes in microbial community structure in Northern hardwood forests. Ecosystems 13:

Vandenkoornhuyse P, Ridgway KP, Watson IJ, Fitter AH, Young JPW. 2003. Co-existing grass species have distinctive arbuscular mycorrhizal communities. Molecular Ecology 12:

Vierheilig H, Coughlan AP, Wyss U, Piche Y. 1998. Ink and vinegar, a simple staining technique for arbuscular-mycorrhizal fungi. Applied and Environmental Microbiology 64: 5004.

Vierheilig H, Schweiger P, Brundrett, M. 2005. An overview of methods for the detection and observation of arbuscular mycorrhizal fungi in roots. Physiologia Plantarum 125: 393-404.

Wilson GWT, Rice CW, Rillig MC, Springer A, Hartnett DC. 2009. Soil aggregation and carbon sequestration are tightly correlated with the abundance of arbuscular mycorrhizal fungi: Results from long-term field experiments. Ecology Letters 12: 452-461.

Yoneyama K, Xie X, Kim HI, Kisugi T, Nomura T, Sekimoto H, Yokota T. 2012. How do nitrogen and phosphorus deficiencies affect strigolactone production and exudation? Planta 235:

Zavalloni C, Vicca S, Büscher M, de la Providencia IE, Dupré de Boulois H, Declerck S, Nijs I, Ceulemans R. 2012. Exposure to warming and $\mathrm{CO}_{2}$ enrichment promotes greater aboveground biomass, nitrogen, phosphorus and arbuscular mycorrhizal colonization in newly established grasslands. Plant and Soil 359: 121-136. 


\section{1}

Figure 1

Figure 1. Soil temperature and water availability in the 2011 growing season. Panels correspond with sites, dotted lines indicate the time period used to estimate soil temperature and matric potential one month prior to plant collection. Because of the different phenology, red lines refer to perennial species and blue lines refer to the annual species.
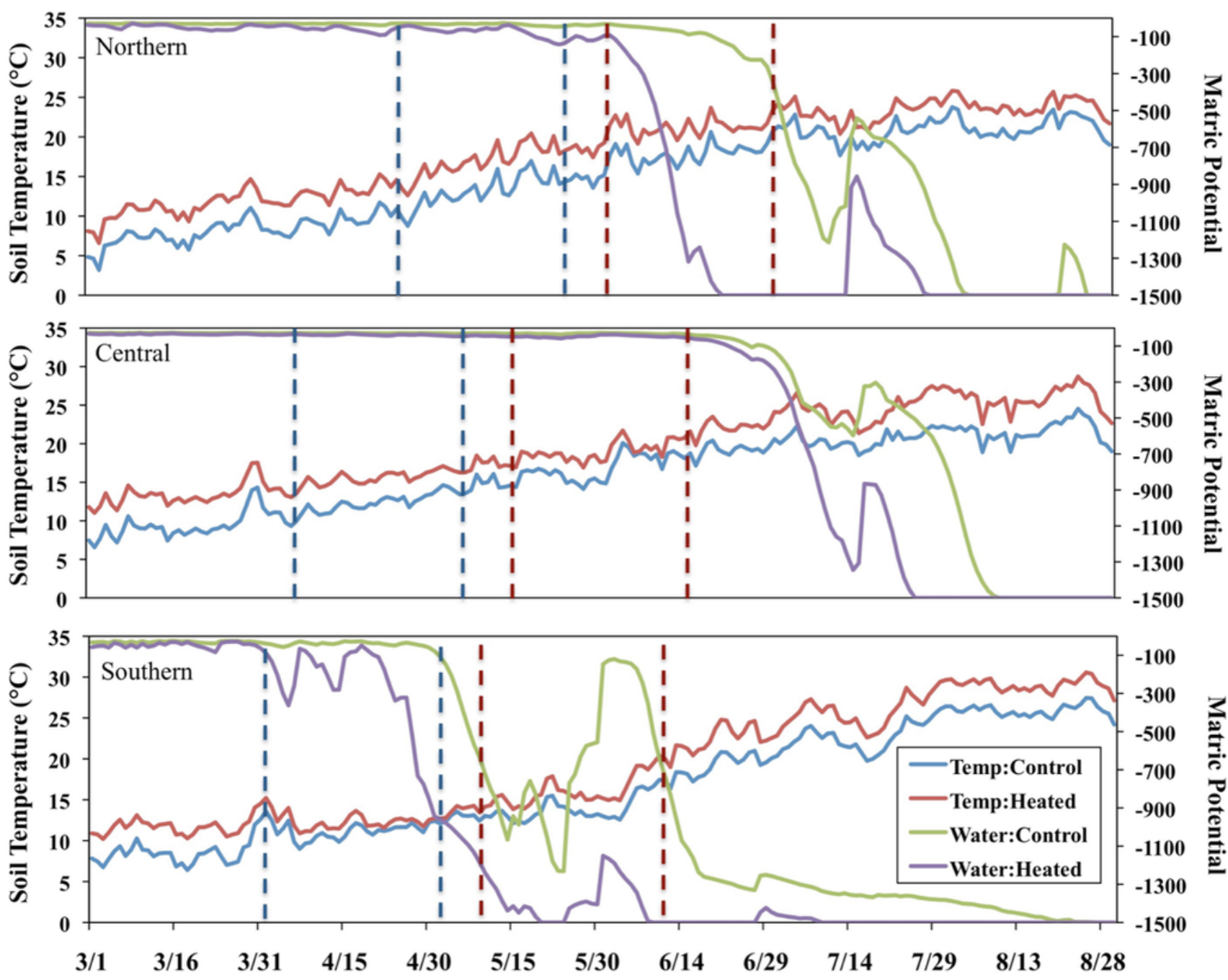
2

Figure 2

Figure 2. Structural equation model of the effect of temperature on AMF colonization and plant biomass. We tested three a priori models that included either soil and plant nitrogen, soil and plant phosphorus, or soil and plant N:P ratios. Each box represents a variable in the model, while each arrow represents a predicted direct effect of one variable on another. A series of connected arrows through multiple variables represent indirect effects. The direct effect plus all the indirect effects of one variable on another is referred to as the total effect.

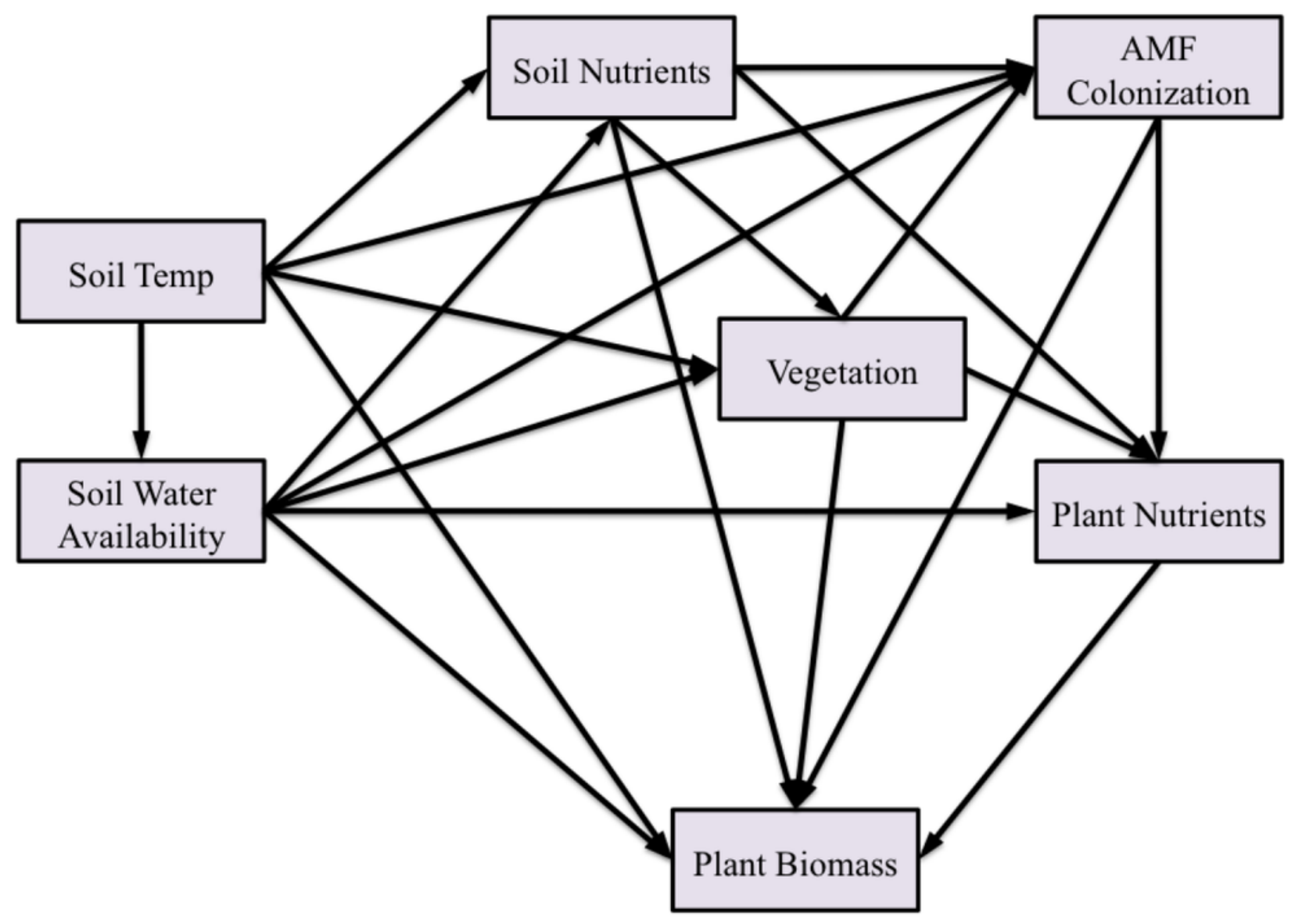




\section{3}

Figure 3

Figure 3. Greenhouse experiment. AMF colonization (a) and aboveground biomass (b) of the four species grown in soil from the three sites (Southern, Central, Northern) in a greenhouse. Different letters indicate significant differences among sites within a species. Error bars represent +/- one SE.
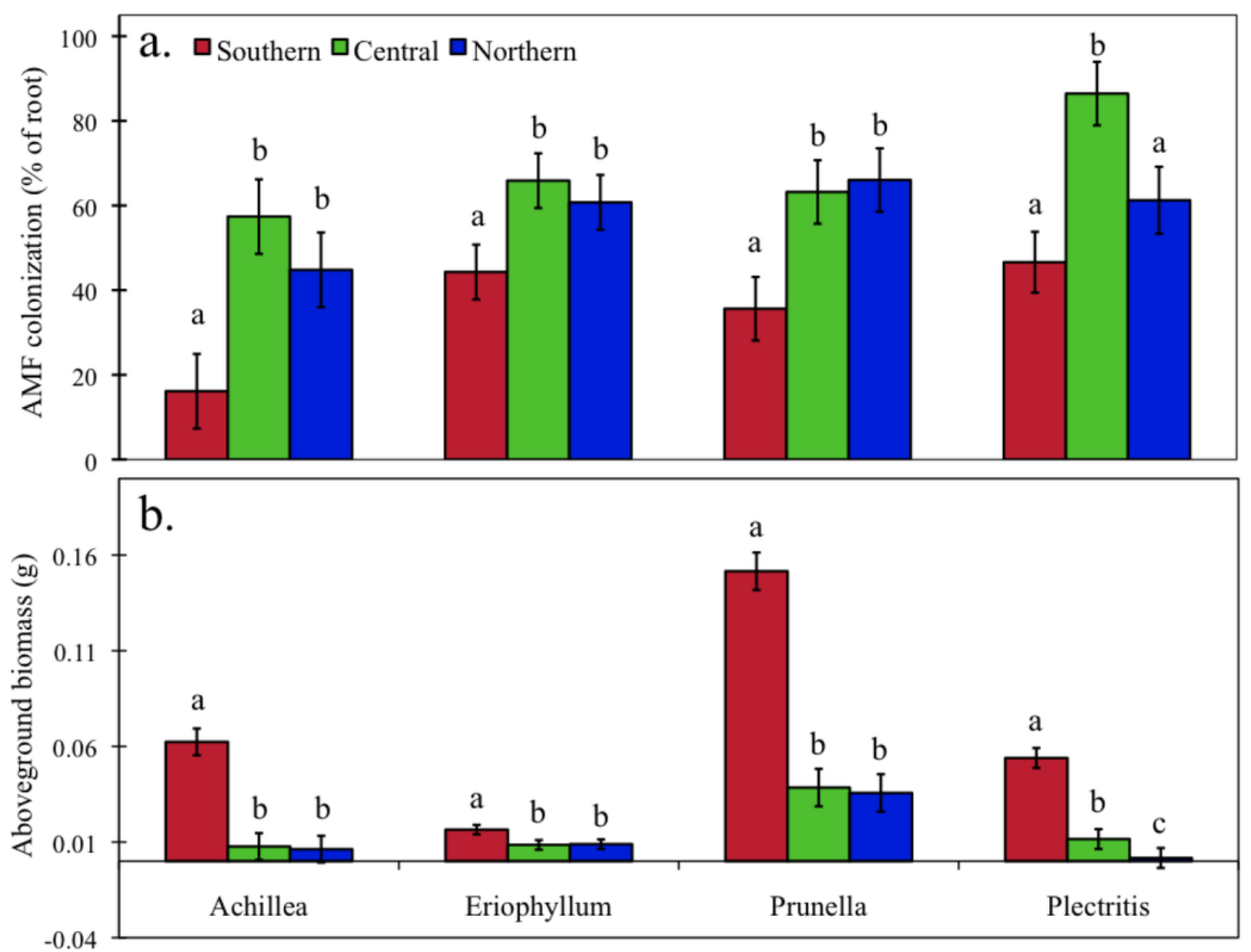
4

Figure 4

Figure 4. The effect of heating on AMF colonization (a) and aboveground plant biomass (b) of the four plant species collected from the three sites ( $S=$ southern, $C=$ central, $N=$ northern). $\mathrm{H} \downarrow$ represents a significant inhibitory main effect of heating. Different letters indicate significant differences among sites within a species. Asterisks represent significant differences between control and heated treatments (** $=P<0.01, *=P<0.10)$. Error bars represent +/- one SE.
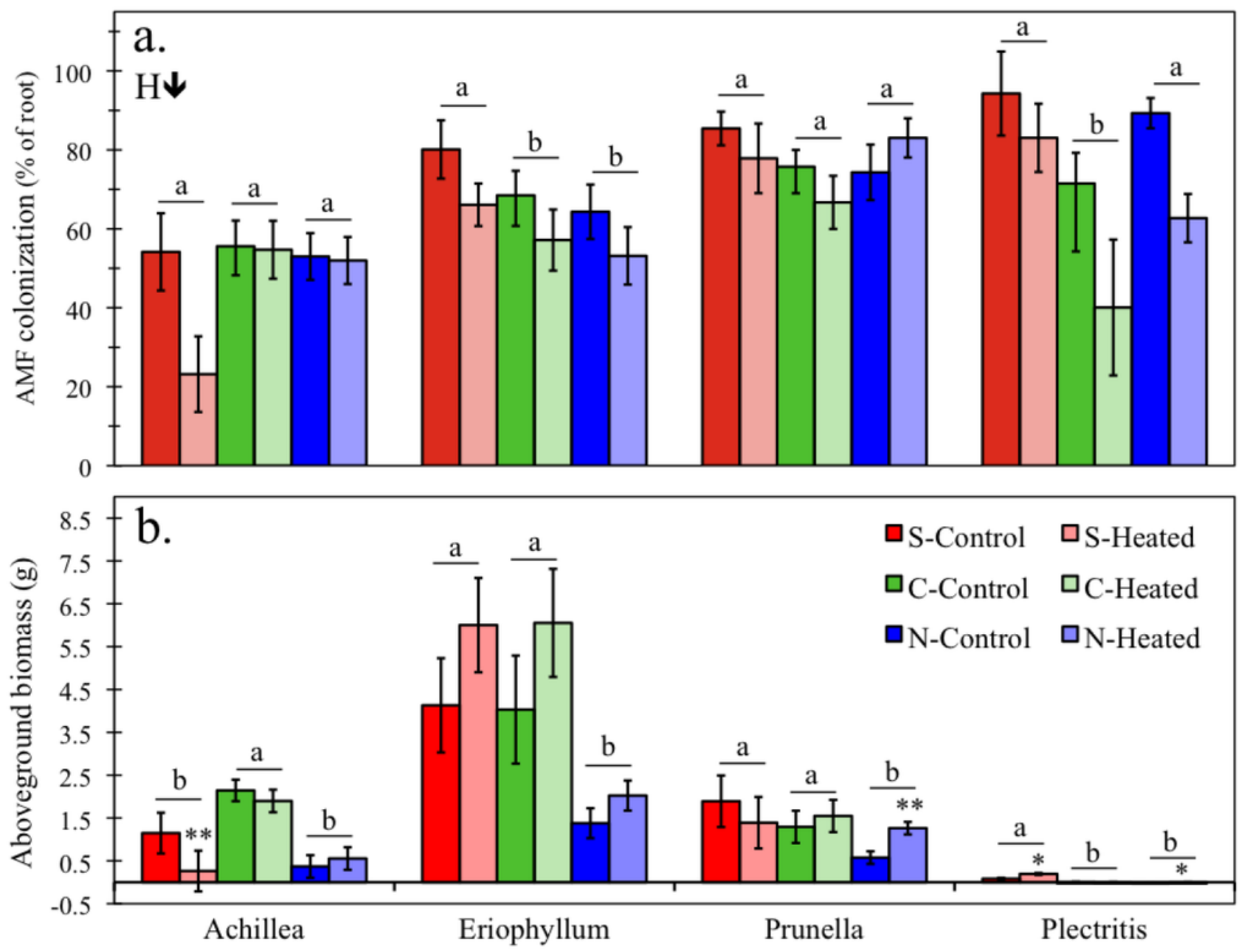


\section{5}

Figure 5

Figure 5. Overall structural equation model including all sites and species. Each box represents a variable in the model, while the number above each arrow represents the value of the standardized path coefficients. The width of each arrow corresponds with the magnitude of the path coefficient, solid lines indicate positive effects, and dashed lines indicate negative effects. Path coefficients not significant at $P<0.10$ are not shown. The italicized, bold number above each box represents the total explained variance $\left(R^{2}\right)$ of each variable.

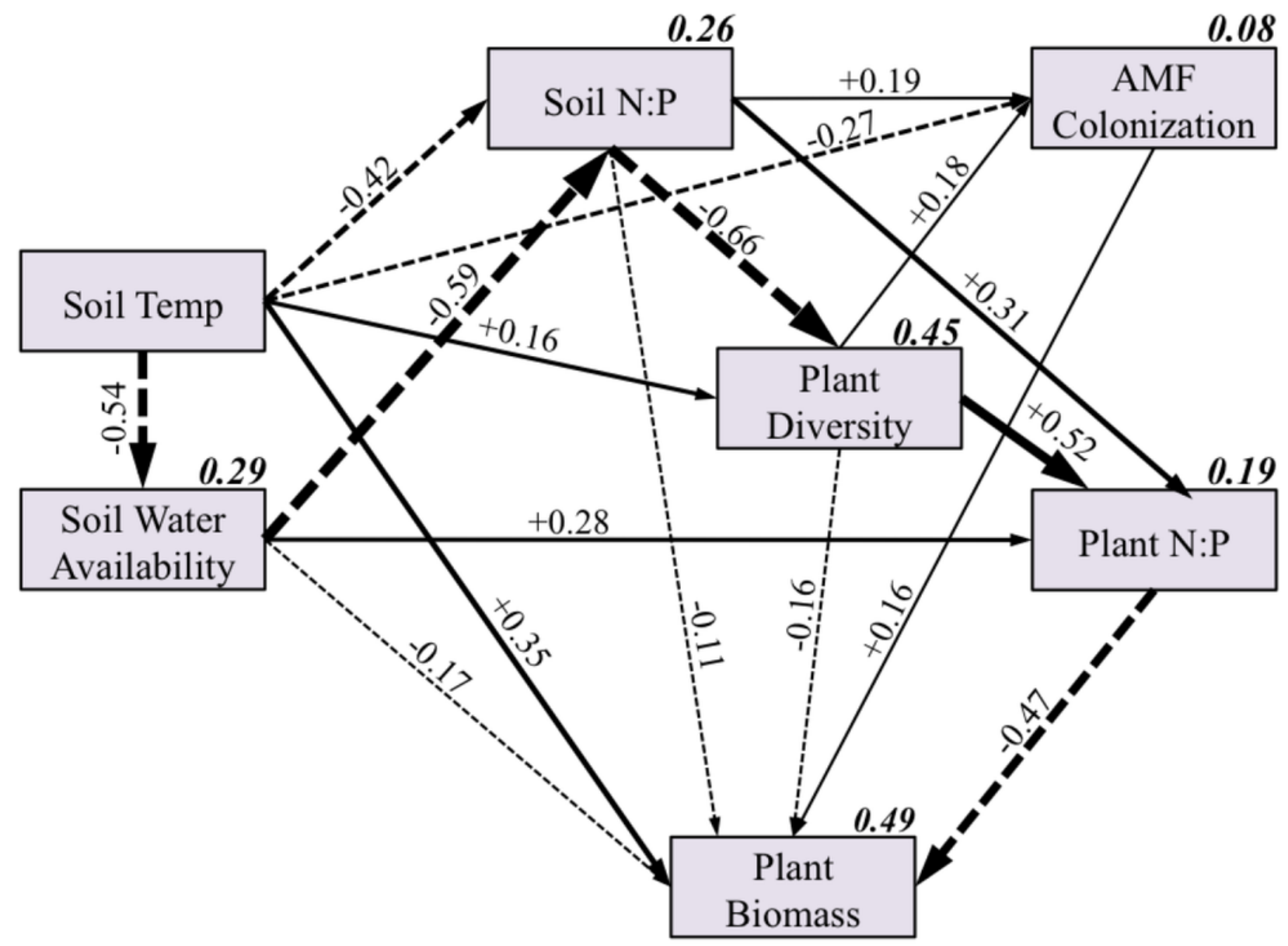




\section{6}

Figure 6

Figure 6. Simplified scheme of direct, indirect and total effects of temperature on AMF colonization and plant biomass for the overall SEM and southern only SEM. Total effect is the sum of direct and indirect effects. Numbers used are extracted from Table 2 and Supporting Information Table S6, respectively.

\section{$\underline{\text { Across all sites }}$}

+0.39 total

Increasing Temp $\stackrel{-0.23 \text { total }}{\longrightarrow}$ AMF Colonization $\stackrel{+0.18 \text { total }}{\longrightarrow}$ Plant Biomass \begin{tabular}{cc|l}
-0.27 direct & +0.04 indirect & \multicolumn{1}{l}{+0.15 direct +0.03 indirect } \\
& +0.35 direct & +0.04 indirect
\end{tabular}

$\underline{\text { Southern only }}$

+0.39 total

\begin{tabular}{|c|c|c|}
\hline \multicolumn{3}{|c|}{-0.38 total } \\
\hline-0.41 direct & +0.03 indirect & +0.483 direct -0.003 indirect \\
\hline & +0.50 direct & -0.11 indirect \\
\hline
\end{tabular}




\section{Table $\mathbf{1}$ (on next page)}

Table 1

Table 1. Site characteristics. Climate data is from the PRISM model for the period 1971 2000 (http://www.prism.oregonstate.edu/). 
1

\begin{tabular}{lccc}
\hline Site & Southern & Central & Northern \\
\hline Latitude & $42^{\circ} 16^{\prime} 41^{\prime \prime} \mathrm{N}$ & $44^{\circ} 01^{\prime} 34^{\prime \prime} \mathrm{N}$ & $46^{\circ} 53^{\prime} 47^{\prime \prime} \mathrm{N}$ \\
Longitude & $123^{\circ} 38^{\prime} 34^{\prime \prime} \mathrm{W}$ & $123^{\circ} 10^{\prime} 56^{\prime \prime} \mathrm{W}$ & $122^{\circ} 44^{\prime} 06^{\prime} \mathrm{W}$ \\
Elevation $(\mathrm{m})$ & 394 & 165 & 134 \\
Mean precip. $(\mathrm{mm})$ & 1598 & 1201 & 1229 \\
Mean mon. temp. $\left({ }^{\circ} \mathrm{C}\right)$ & 12.2 & 11.4 & 9.8 \\
Max. mon. temp. $\left({ }^{\circ} \mathrm{C}\right)$ & 19.9 & 17.3 & 15.3 \\
Min. mon. temp. $\left({ }^{\circ} \mathrm{C}\right)$ & 4.1 & 5.3 & 4.9 \\
Sand $(\%)$ & 31.4 & 36.4 & 73.9 \\
Clay $(\%)$ & 22.5 & 11.9 & 2.4 \\
Silt $(\%)$ & 46.0 & 51.6 & 23.7 \\
Total soil nitrogen $(\%)$ & 0.3 & 0.5 & 0.3 \\
Total soil carbon $(\%)$ & 3.4 & 7.3 & 4.9 \\
N:P ratio of soil & 5.4 & 1.1 & 1.7 \\
pH & 6.5 & 5.8 & 5.6 \\
\hline
\end{tabular}

2

3 


\section{Table 2 (on next page)}

Table 2

Table 2. Standardized direct, indirect, and total effects of the overall N:P ratio Structural Equation Model. 


\begin{tabular}{|c|c|c|c|c|c|}
\hline Effect of Variable 1 & on & Variable 2 & $\begin{array}{l}\text { Direct } \\
\text { Effect }\end{array}$ & $\begin{array}{c}\text { Indirect } \\
\text { Effect }\end{array}$ & $\begin{array}{l}\text { Total } \\
\text { Effect }\end{array}$ \\
\hline Soil Temperature & $\rightarrow$ & Soil Water Availability & -0.54 & $\mathrm{~N} / \mathrm{A}$ & -0.54 \\
\hline Soil Temperature & $\rightarrow$ & Soil N:P & -0.42 & 0.32 & -0.10 \\
\hline Soil Temperature & $\rightarrow$ & Plant Diversity & 0.16 & 0.00 & 0.26 \\
\hline Soil Temperature & $\rightarrow$ & AMF colonization & -0.27 & 0.04 & -0.23 \\
\hline Soil Temperature & $\rightarrow$ & Plant N:P & $\mathrm{N} / \mathrm{A}$ & -0.02 & -0.02 \\
\hline Soil Temperature & $\rightarrow$ & Plant Biomass & 0.35 & 0.04 & 0.39 \\
\hline Soil Water Availability & $\rightarrow$ & Soil N:P & -0.59 & N.A & -0.59 \\
\hline Soil Water Availability & $\rightarrow$ & Plant Diversity & -0.08 & 0.39 & 0.31 \\
\hline Soil Water Availability & $\rightarrow$ & AMF colonization & -0.03 & -0.05 & -0.08 \\
\hline Soil Water Availability & $\rightarrow$ & Plant N:P & 0.26 & -0.02 & 0.24 \\
\hline Soil Water Availability & $\rightarrow$ & Plant Biomass & -0.17 & -0.11 & -0.28 \\
\hline Soil N:P & $\rightarrow$ & Plant Diversity & -0.66 & N/A & -0.66 \\
\hline Soil N:P & $\rightarrow$ & AMF colonization & 0.19 & -0.12 & 0.07 \\
\hline Soil N:P & $\rightarrow$ & Plant N:P & 0.31 & -0.34 & -0.03 \\
\hline Soil N:P & $\rightarrow$ & Plant Biomass & -0.11 & 0.13 & 0.02 \\
\hline Plant Diversity & $\rightarrow$ & AMF colonization & 0.18 & N/A & 0.18 \\
\hline Plant Diversity & $\rightarrow$ & Plant N:P & 0.52 & -0.01 & 0.51 \\
\hline Plant Diversity & $\rightarrow$ & Plant Biomass & -0.16 & -0.21 & -0.37 \\
\hline AMF colonization & $\rightarrow$ & Plant N:P & -0.06 & N/A & -0.06 \\
\hline AMF colonization & $\rightarrow$ & Plant Biomass & 0.15 & 0.03 & 0.18 \\
\hline Plant N:P & $\rightarrow$ & Plant Biomass & -0.47 & $\mathrm{~N} / \mathrm{A}$ & -0.47 \\
\hline
\end{tabular}

2

3 